\title{
METHODS AND APPROACHES OF COMPLEXITY THEORY AND FUZZY LOGIC FOR INTENSITY OF UNIVERSITY RESEARCH IN TERMS OF CREATIVE WORK TO BE ESTIMATED
}

\author{
Marina Galiakhmetova \\ Kalashnikov Izhevsk State Technical University, Izhevsk, Russian Federation \\ Vladimir Koretskiy \\ Kalashnikov Izhevsk State Technical University, Izhevsk, Russian Federation \\ Irina Mardanova \\ Bashneft-Treid LTD Udmurtia Regional Brunch, Izhevsk, Russian Federation \\ László Józsa \\ J. Selye University, Komarno, Slovakia
}

\begin{abstract}
This article describes the main approaches to research in terms of creative labor regulation and time study. Definition of a creative labor and brain-work product as a subject of regulation and work intensity estimation was developed. The method for creative brain-work intensity estimation was based on complexity theory, which enables the evaluation of the complexity of creative brain-work results and time expenditure. Because of the appropriateness of linguistic expert assessments while labor intensive creative work is carried out, the methods and approaches of fuzzy logic were suggested to assess the Competence Complexity of the creative work product. Based on statistical and expert models, a regression was built to estimate time expenditure dependence of the creative brain-work expected outcomes on Competence Complexity. The resulting dependency allows the estimation of the time spent on the research project based on the estimation of the expected project results.
\end{abstract}

Keywords: Rationing of labor, Creative work, Assessment effort, Complexity theory, Fuzzy logic, Work measurement, Work norm-setting, brain-work, Time study.

DOI: http://dx.doi.org/10.15549/jeecar.v6i1.241

\section{INTRODUCTION}

Research is an integral part of the Russian educational system. Since Russia's accession to the Bologna process, when so called "specialitet" (the Russian sound of "specialists training") Soviet traditional education system turned into two-staged baccalaureate and magistracy, this issue has gotten more crucial. 
While this has been going on, the rationing and estimating of research on creative work efforts and time study have gotten more essential. At least it is useful to determine the time-frame of scientific-research for theses to be prepared to defense. So, talking about research intense estimation, we mean and use the term "creative work".

Russia has several hundred regulatory legal acts, departmental recommendations and other documents and papers defining the time amounts for given work, labor standards, and personnel capacity rate in various branches of the economy. However, despite the growing importance of creative work from the point of view of enterprises or even national economic efficiency, work measurement remains out of state or even corporate regulation.

And the very notion of "creative work" is presented in the Russian legal framework too sparsely. It is indirectly presented in the State Labor Code of the Russian Federation. Along this way, this provision of the law is limited to mass media, film making, TV, video shooting, different kinds of troupes. circuses, performance folks and showmen. Labor Code 52.1 Chapter defines the special features governing the scientists, heads of scientific organizations and their deputies working, whose activities can be described as "creative".

In addition, creative copyrights are governed by Russian legislation. In recent years, different departmental rules and codes that establish professional standards and requirements for creative workers came into life. But, at the same time, creative work measurement and intensity are beyond the Russian legal system till nowdays.

Obviously, it is a serious omission while the importance of creative work continues to rise. According to some researchers, creative class representatives are gradually replacing the socalled traditional middle-income employees, who are working in service. Creative activity statistics are not yet well established, but their appearance is significant. Florida (2012) defined creative economy branches and put out new class structure, its components and dynamics. He mentioned creative class and its supercreative core as well as maintain class. Working class and farming are the only previous classifications. At the end of the twentieth century there was a qualitative shift, including the boom of the creative class and a decline in the number of farmers and workers. Since 1980 the share of the service employment has gone down. That is how the current innovative economy in which a growing number of people earn through creativity seems, noted Yasin former Minister of economy of the Russian Federation (Yasin, 2007).

Over the last century in the developed countries' economics the proportion of creative and brain workers increased from $10 \%$ to at least $90 \%$. In the near future, this indicator could reach 95 percent (Yu, et al., 2016; Kutsenko, Udovitchenko, \& Opaleva, 1998). At the same time, in 1990s in the United States, Japan, Germany, and the UK, the number of creative workers stood at $40-50 \%$ of total employment. By 2020 this indicator can get to 55 - 60\%. In general, creative work has greater efficiency than traditional, manual labor, because $90 \%$ of GDP in developed countries is provided by brain-workers.

In the Russian Federation, despite the serious economic and financial challenges, the State remains a major investor in creative projects in the arts and media, and it is the main financial source of scientific research, including in education.

According to official data, over 732,000 Russians are employed in scientific research (Rosstat, 2017). Based on these data, it can be concluded that intensive estimation and creative work measurement are crucial issues for today. This might create a scientifically grounded basis for time study and creatives motivation to be carried out. The latter aspect is directly related to the fair and adequate compensation for work.

\section{CREATIVE WORK DEFINITION AN ITS CLASSIFICATION}

Since the creative research process or act of creation may not always be observed and is beyond direct measurement, it often lacks principle repeatability; it is unique, and sometimes the result of one is a product of "insight". Some authors, as we show below, come to the creative work measurement neither 
through time study nor physiological research but basically on creative work results assessment and estimation. Hence, the definition of "creative work" and "results of creative work" in the term of norm-fixing and time expenditure is currently becoming more crucial.

Kuschnir (2007), representative of a leading Russian scientific school which focused on labor research, citing Changli (1973), put forward an idea to define "creative work" as an activity with a progressive element of novelty, when qualitatively new inventory items and cultural wealth come up, and these new products enable one to meet just emerged needs of society. In the process, creative work generates some results for society's needs to be boosted.

According to Kushnir (2007) complex brain work or R\&D aimed to gain new knowledge. This is the essence of the creative activities. He defines the content of creative work as an intellectual activity, which includes not only fruitful thinking, but purposeful thinking also.

So, we can define creative work as the creation and interpretation of cultural values, which should be understood to mean the new knowledge, is able to meet new needs of society and generate new requirements to meet the needs this knowledge. Art crafts, culture and art performance, buildings, constructions, innovative high-tech projects and even technologies are only applications of the new knowledge, but not creative work gains in and of themselves. And this part of human activity, as an element of management or handicraft labor can be pulled through norm-fixing and time expenditure estimation with traditional approaches and methods.

Kushnir (2007) carried out creative work classification by type of activity, which is summarized here:

- the first type of creative work is scientific activity dedicated to basic research;

- the second type of creative work refers to applied research to transform knowledge into new technologies;

- the third kind of creative work is art and cultural values creation;

- the fourth type of creative work is an activity, which is often referred to as art for short-term needs of the people to be met through entertaining pop-culture performance;

- the fifth creative work is innovative enterprise and entrepreneurial activities, based on new marketing techniques.

Genkin (2007), a Russian labor economist, classifies "creative work" as follows: regulated or $\alpha$-work, creative - $\beta$-work, and spiritual - $\gamma$ work. Serbinovskiy, Kalmykova and Botashev (2013) adjusted this classification, separating $\beta$ work into two distinct components: $\beta_{1}$-work, or creative change regulated processes based on conventional knowledge, and $\beta_{2}$-work, which involves creativity for the creation of new knowledge and new ways of management. As the authors note, the result of this work category is knowledge and different kind of information with a high level of novelty for use in business practices and on the market, with intellectual rights protection.

It would be appropriate to determine what we mean by the term "new knowledge", but we leave it outside this study, focusing on an intuitive understanding of what is it. In this paper, we use this term as the identification of creative work result or product. Either way, the generation of new knowledge requires a high level of knowledge, and competencies in certain branches of activity and creativity.

\section{THE MAIN ISSUES FOR CREATIVE WORK TO BE ESTIMATED}

As creative activity is gaining a priority productive capacity of society, creative work measurement and time study in this branch of human activity are becoming increasingly important. Many academic schools in Russia and overseas accept this fact (Kleiner, 2004; Makarov \& Kleiner, 2007; Makhlup, 1962; Uvarova, 1982; Botashev, 2011). Nevertheless, despite the presence of many studies in this area, we have more questions than answers. In most areas of creativity there is a lack of generalized, reasonable and statutory labor standards and methods for the intensity of creative brain-work to be estimated. Even though in Russia scientific activity remains essentially public bearing in mind the major sources of funding, there are no generalized, 
justified and regulatory enshrined labor standards concerned with cross-industry, sectoral, professional and other levels.

The causes of the methodological problems of rationing creative work are following (Kushnir, 2010):

- high variety of jobs to do and rare occurrence;

- considerable dependency costs and results from the employee's personal merits and diverse conditions of creative work;

- the specific nature of the creative work, for example, the creativity involuntary goes on beyond working time;

- high risk of getting a negative result due to high novelty studies and project objects;

- collective work management when interdisciplinary knowledge to be used and moral-psychological climate have significant impact on outcomes.

Kushnir (2010), with reference to the Russian psychologist Luck (1978), notes similarities in the stages of scientific and artistic creativity:

1. Necessary knowledge accumulation and skills for gaining a clear understanding and for tasks to be set;

2. Focusing on a search for extra information;

3. The seeming escape of task thinking and switching to other activities or in other words, a so-called "incubation period";

4. "Insight", which looks like a logical gap or leap in the thinking;

5. Checking the results.

As Kushnir (2010) notes, although stages 1, 2, and 5 may well be regulated, little do we know how to describe and set the standard for processes identified as stages 3 and 4 . The result of this is new product of complex brain-work. Without the ability to normalize the entire process of creativity, we, nevertheless, encounter with the creative work result with special characteristics at the very end .

Richardson (1971), assuming a linear dependence between the quantity of labor actions and time expenses for their execution, developed a method for standardizing indirect jobs, based on multiple regressions.

In this regard, among the three main methods of norm-fixing, neither computationallyanalytical nor experimentally-statistical methods are proper, but a judgmental method is proper for creative work estimation. The constraints of the first two approaches arise from the fact that they rely on the monotony of work and frequent repeatability of the operations. At the same time, as noted by Kushnir (2010), creative work or brain-work is possible only through one's result or product.

Hence, the norm regulation of creative work is done through evaluation of the result, or in the above defined terms "creative work" and "product of creative work"; it is the complexity of "new knowledge" which should be estimated to define intensity of creative work and carry out time study analysis.

\section{Creative Work Measurement through Complexity Attribute}

The concept of "complexity" in the context of the valuation and assessment of laborintensiveness appeared in "complexity theory" (Sharin, et al., 1999). The authors suggested this indicator for estimating effort of an intricate piece of machinery manufacturing. This is an "invariant" and inherent property of product, which is not affected by external conditions, labor management, and is not bound to cost, qualification of personnel, and other subjective categories.

The authors of "complexity theory" have developed the theoretical apparatus for this indicator to be calculated and how to use it. This method of work measurement was named as a method of evaluating complexity.

The "complexity" of the product of labor is determined regardless of the technological process.

Universality theory allows to adapt it for time study and estimating the intensity of the creative work. Indeed, in this case, the result of the creative work or "new knowledge" can be considered as a complex, intricate piece of machinery manufacturing, and the designer as the expert group according to idea of estimation of brain work through expert evaluation.

Let us briefly describe the main ideas of the 
complexity theory. The core issue of defining the product manufacturing labor-intensiveness is a study of dependence:

$$
T=f(C)
$$

Here $C$ is the "complexity" of the product, and $T$ is the laboriousness. In the original method itself, it is about the complexity of the intricate piece of machinery manufacturing, but to generalize the idea, the broader term "product of labor" is used.

The authors offer a study of the dependence statistical method. To determine the complexity indicator the model was proposed:

$$
C=C_{s} \cdot K_{1} \cdot K_{2} \cdot \ldots \cdot K_{n} \text {, }
$$

Here $C_{s}$ is the structural complexity of the product, and $K_{i}$ - coefficients which enable the impact of different factors to be considered.

According to the theory of complexity, laboriousness $T$ is determined based on manufacturing data. Thus, in the studied paired values of $\mathrm{T}$ and $\mathrm{C}, \mathrm{T}$ (laboriousness) is laborintensive, and $\mathrm{C}$ (structural complexity) is calculated in accordance with Formula 2.

As shown by the authors of "complexity theory", laboriousness of the product and its complexity are random variables with a high degree of correlation. This allows the complexity to be considered as an indicator of labor intensity, and can be determined with the regression dependence. The authors opted for linear regression model (3) the next expression:

$$
T=a+b \cdot C
$$

Here $a$ and $b$ are regression coefficients. This dependence has allowed the authors to develop a method of norm-fixing, named complexity evaluation method. The empirical dependence $T(c)$ seen in Figure 1 enables laboriousness definition through the result of labor product complexity estimation.

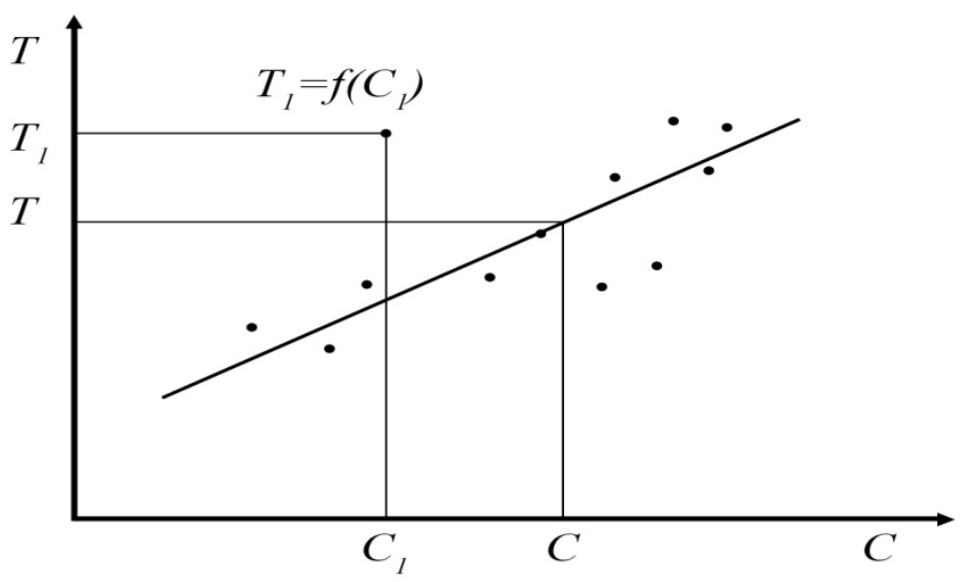

Figure. 1. Dependence $\operatorname{Tof} f(C)$

It seems fair that complexity theory can become the basis for estimating effort of creative work, including research and brainwork. For this purpose, it is necessary to make some generalizations.

In complexity theory, "structural" complexity $\left(C_{S}\right)$ in equation (2) is a function of the number and shape of the basic elements of the manufacturing piece outline. In other words, it is about some gathered information or knowledge about the product of labor.

If we are talking about the creative work product which is "new knowledge", instead of "structural" complexity, Competence Complexity sounds more accurate and includes knowledge and competencies required to sort out intellectually demanding tasks with benefits. As noted by some authors, the fact that creative work requires longtime practice, high qualifications and is one of the most difficult 
forms of human activity, is well known. Creative work is typical for engineers, architects, inventors, researchers, writers, composers, painters and artists whose work is not possible without vast amounts of knowledge, attentiveness, neuro-emotional state, new algorithms development, and unregulated intensity of activity. So, instead of "structural" complexity we consider $C_{c}$ or "Competence Complexity". The $C_{c}$ indicates the level of skills, time of one's training, and volume of knowledge required to select a creative task.

The main point that needs to be focused on, with regard to regression, is that it should be nonlinear. We use the exponential regression because with the growing volume of information, the number of logical operations to process data is increasing exponentially.

In practice, this kind of assessment is carried out by venture investors when they pick out creative projects in which to invest. The crucial indicators while this process goes on are managerial abilities and research skills of the teams. The similar requirements are included, for example, into the rules of Russian Innovative Foundation Skolkovo participation recognition It defines specifically that key researchers, developers and project managers, applying for an innovation center residency, should have the necessary resources for the successful implementation of the project knowledge, scientific or industrial experience and entrepreneurial capacity.

There are serious world regulatory practice requirements, rules, and standards of professional competence, and the competence of managers with a high creative component, at least for scientific and applied research. They are governed by national systems of certification and a so-called body of knowledge.

Currently, in the Russian Federation a professional standard for scientists is being developed. Even though this is a draft, based on the structure of already existing professional standards in Russia, it must contain a description of labor functions for scientific research to be carried out successfully in accordance with specific levels of qualification.

Regarding creative work, the coefficients $K_{1}, K_{2}, \ldots, K_{n}$, are determined by the specifics of the goals. If they are about research activities, the factors which impact the duration of project stages should be considered. Russian researchers Durnev and Zhdanenko (2016) define nine factors, but in this work, we only focused on three factors, including novelty, prospectivity and complexity of new knowledge in terms of creative work results (Kushnur, 2010). This seems reasonable because consumers are not interested in the process but in value that makes them pay.

\section{DEFINITION OF COMPETENCE COMPLEXITY $\left(C_{c}\right)$ OF THE CREATIVE WORK RESULTS}

Typically, when creative work is estimated, experts in a branch of knowledge try to approximate time of work. This approximation is getting the basis of the creative work normfixing (Feoktistova, 2014). These approaches are well described in the academic sources. However, due to the uniqueness of each issue, specialists select the way and means to gain results, which can seriously reduce or increase the time to get results.

In our opinion, the amount of time performers work on the accumulation of experience and competencies necessary for successful performance should be considered. Expert assessment implies a certain fuzziness, nonstrict reasoning, linguistic characteristics and quality estimating of creative challenges and logistical means. To solve this task, we offer to use the mathematical apparatus, known as fuzzy logic.

Firstly, principles of fuzzy logic have been formulated by American scientist Zadeh (2002). Currently fuzzy logic is applied in the automotive, aerospace and transportation industries, robotics, risk assessment, and management, including staff assessment (Yu \& Shevchenko, 2009). In the Ph.D thesis of Packlin (2004), fuzzy logic ideas have been used to define the time expenditure of engineering products manufacturing, which, as noted by the author, allows to estimate time norms without designing the engineering process.

In this article we do not point out the nuances of fuzzy logic, as they are well known. We just note that the dependence $\left(C_{c}\right)$ of the input and output variables describing the complexity of creative work results should be defined: 


$$
C_{d}\left(y_{1}, y_{2}, \ldots, y_{m}\right)=F\left(x_{1}, x_{2}, \ldots, x_{n}\right) .
$$

Here $\left\{X_{1} \ldots X_{n}\right\}$ are evaluated indicators and $\left\{y_{1} \ldots y_{m}\right\}$ are output variables.

Output values, fuzzification and defuzzification parameters in accordance with linguistic rules, determine $C_{c}$ - "Competence Complexity" of creative work results or "New Knowledge", and this is an intensity measure of the creative work.

\section{AN ALGORITHM FOR CREATIVE WORK INTENSITY ESTIMATION}

Based on the above described ideas, the algorithm of creative work estimation can be developed.

The first step includes statistics accumulation, including information on creative projects and time expenses for their realization.

The second step is a rating of "Competence Complexity" of creative work results, including, for example, such categories as the complexity novelty and market significance of knowledge.

The third step includes the quantitative interpretation of qualitative assessments with the approaches of fuzzy logic and complexity of new knowledge definition $C_{c}$, through the parameters of estimation $C, K_{1}$ and $K_{2}$.

The forth step is about $T=f(C)$ calculation with exponential regression analysis when $T(C)=a \cdot e^{b \cdot c}$. Here $T$ is the laboriousness; $a$ and $b$ are regression coefficients. This function allows evaluating the laboriousness of creative work, with the expected complexity of the result in the term of "new knowledge".

The advantages of this model are following:

- a relatively simple mathematical model;

- initial statistical data can be gathered concerning relatively non-unique creative projects, including studies of masters and postgraduate studies, and journalistic inquiry when novelty, viability and Competence Complexity can be estimated very easily;

Function $T(C)=a \cdot e^{b \cdot c c}$ has a universal nature, regardless of industry and "genre" of creativity because it explains the dependence of the laboriousness from an invariant indicator that describes the product of labor.

\section{STUDY OF INTENSITY OF CREATIVE WORK DEPENDENCE FROM THE COMPLEXITY OF THE PRODUCT OF CREATIVE WORK BASED ON STATISTICAL MODEL}

Here we put out results of creative work intensity estimation for research and development, based on statistics obtained by Durnev and Zhdanenko (2012). The survey was conducted regarding ordinary research and development.

Table 1. Input and output parameters for the creative work product assessment

\begin{tabular}{|l|l|l|l|}
\hline Variable & Title & Linguistic term & Peer review \\
\hline$C$ & $\begin{array}{l}\text { The complexity of } \\
\text { knowledge }\end{array}$ & $\begin{array}{l}\text { Simple, } \\
\text { Medium, } \\
\text { Complex }\end{array}$ & $0-10$ points \\
\hline$K_{1}$ & The novelty of knowledge & $\begin{array}{l}\text { Low, } \\
\text { Medium } \\
\text { High }\end{array}$ & $0-10$ points \\
\hline$K_{2}$ & $\begin{array}{l}\text { Knowledge } \\
\text { perspectiveness } \\
\text { Medium, } \\
\text { High }\end{array}$ & $0-10$ points \\
\hline$C_{c}$ & Competence Complexity & $\begin{array}{l}\text { Low, } \\
\text { Medium, } \\
\text { High }\end{array}$ & $0-10$ points \\
\hline
\end{tabular}


The complexity of the creative work product at each stage is assessed based on the three following options: the complexity, novelty, and prospect of application of the new knowledge based on linguistic assessments under fuzzy logic.

To determine the complexity of the "new knowledge" at every stage of research and development, it is necessary to determine the rating interval with maximum and minimum point values of the following coefficients:

- $\quad C$ is the complexity of knowledge;

- $K_{1}$ is the novelty of knowledge;

- $K_{2}$ is the knowledge perspectives.

Evaluation methodology is described by Karjakin and Grubov (2012). To simplify results lets us define the limitation of expert rating with interval from 1 to 10 with step 1 point (Table 1 ).

The above-mentioned coefficients and output function $C_{c}$ are described through a multitude of linguistic variables with its membership function with values ranging from 0 to 1 . Figure 2 presents options related to membership functions, which in practice should be based on expert assessments.

Knowledge complexity

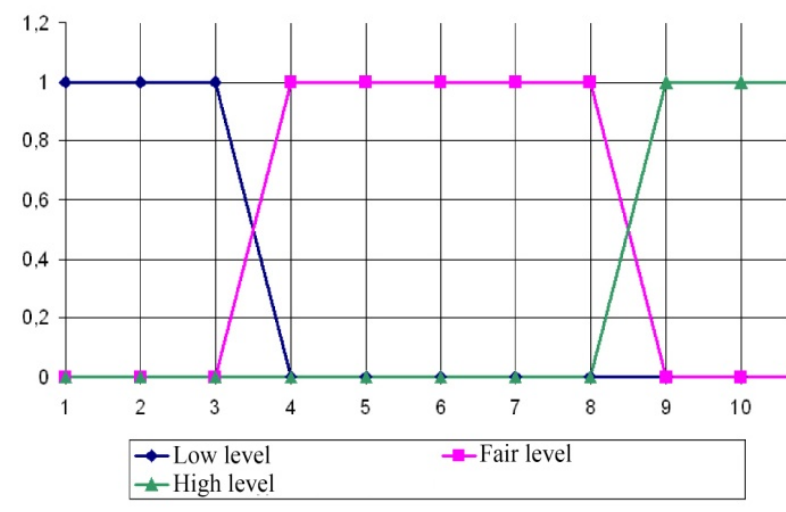

Knowledge novelty

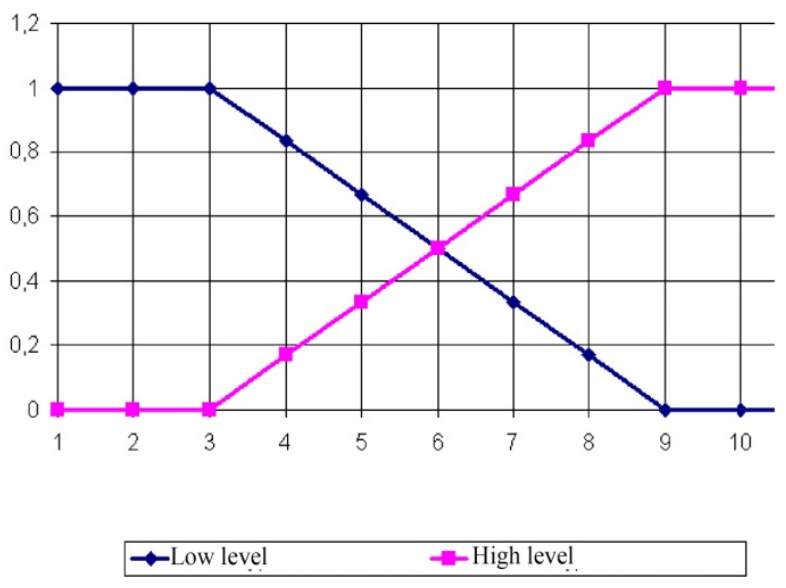

Knowledge perspectivity

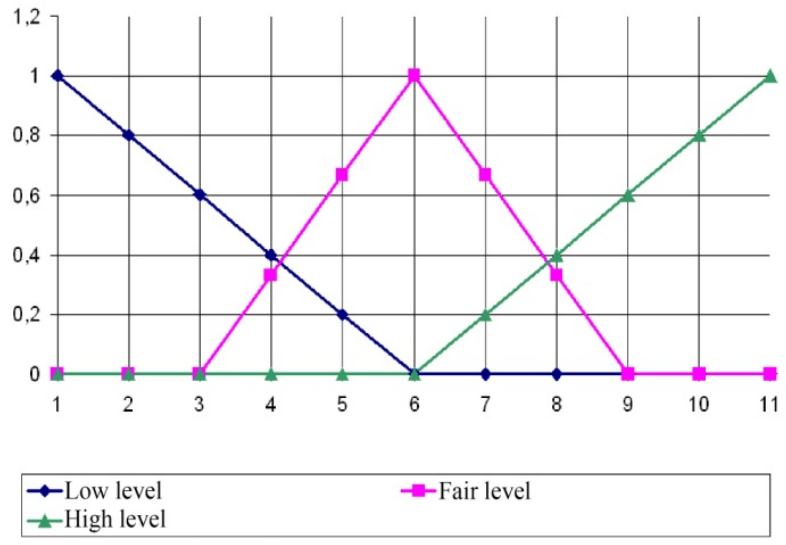

Knowledge complexity

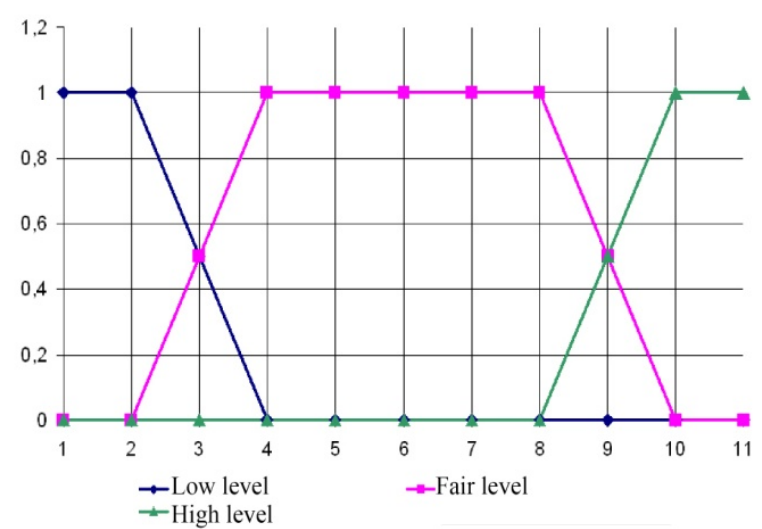

Figure 2. Hypothetical membership functions of linguistic terms 
Rules for assessing new knowledge obtained as a product of creative work should be as follows:

- if the complexity of knowledge is low, prospect is low, and novelty is low - the Competence Complexity is low;

- if the complexity of knowledge is the fair, novelty is low, and the prospect is low then Competence Complexity is fair;

- if the complexity of knowledge is great, novelty is low, and perspectiveness is low, the Competence Complexity can be low, can be fair or can be high (maybe), etc.

The numerical interpretation of "new knowledge models" presented in the table was implemented with the Mamdani method:

$$
C=\frac{\int_{x l}^{x u} \mu(x) x d x}{\int_{x u}^{x l} \mu(x) d x}
$$

where $v(X)$ - is a function which describes the "model" of new knowledge obtained because of the creative work. For this simple twodimensional model, $C_{C}$ is the coordinate of the center of mass of these objects. Results of the de-fuzzification are presented in Figure 3 and Table 2 with Durnev and Zhdanenko (2012) statistics. The values of the $C$ calculated during de-fuzzification are shown in Table 2. a)

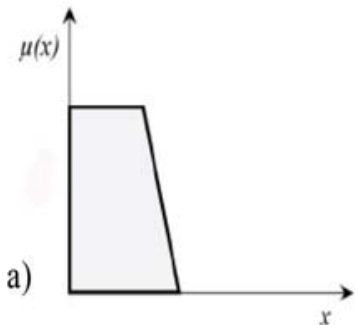

c)
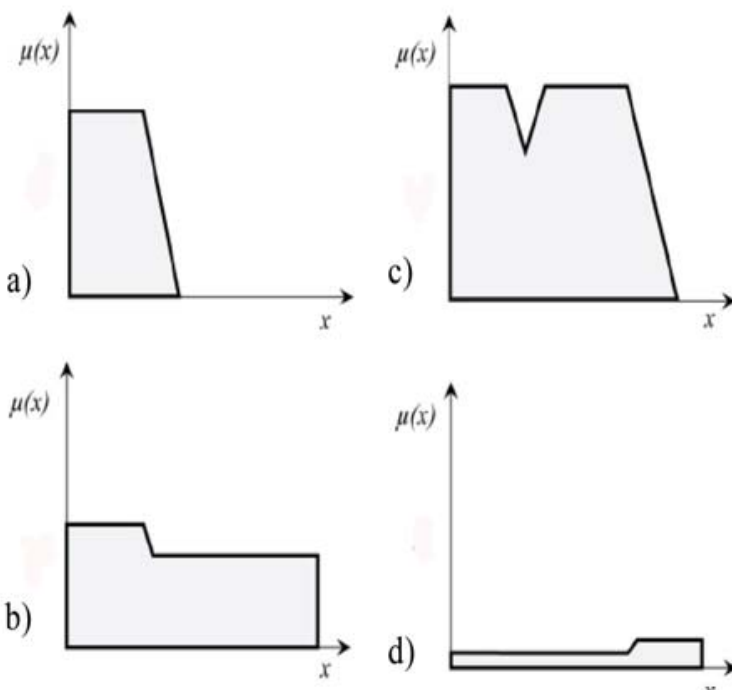

d) e)

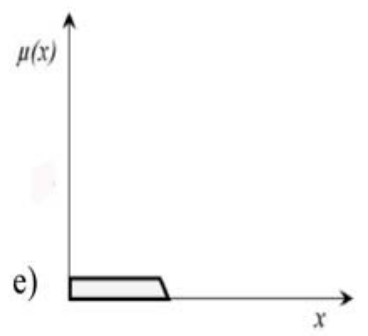

g)

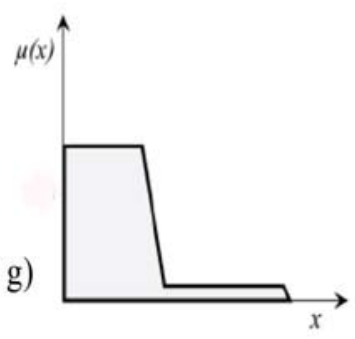

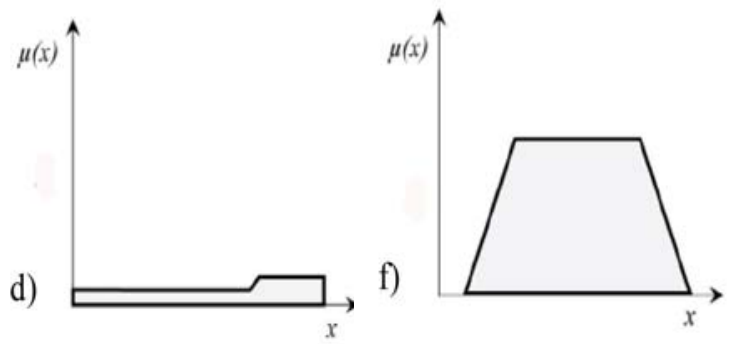

Figure 3. De-fuzzification for each stage of research and development under the "complexity of knowledge", "novelty" and "perceptively": a) 2, 1, 1; b) 6, 1, 4; c) 6, 4, 5; d) 7, 7, 7; e) 2, 3, 3; f) $7,6,5 ;$ g) $2,5,6$ 
Table 2. Expert evaluation of the arithmetic means of research and development creative stages time length and de-fuzzification results

\begin{tabular}{|c|c|c|c|c|c|c|}
\hline \multirow[t]{2}{*}{ R\&D Stages } & \multirow{2}{*}{$\begin{array}{l}\text { Duration } \\
\text { of the R\&D } \\
\text { Stages } \\
\text { (days) }\end{array}$} & \multicolumn{3}{|c|}{ Expert Score (Points) } & \multirow{2}{*}{$\begin{array}{l}\text { Fuzzification } \\
\text { model }\end{array}$} & \multirow[t]{2}{*}{$C$} \\
\hline & & $\begin{array}{l}\text { The } \\
\text { complexity } \\
\text { of } \\
\text { knowledge }\end{array}$ & $\begin{array}{l}\text { The } \\
\text { novelty of } \\
\text { knowledge }\end{array}$ & $\begin{array}{l}\text { Perspectiv } \\
\text { es of the } \\
\text { knowledge }\end{array}$ & & \\
\hline $\begin{array}{l}\text { Understanding the } \\
\text { purpose and objectives of } \\
\text { the R\&D and demands to } \\
\text { scientific and practical } \\
\text { results }\end{array}$ & 12.68 & 2 & 1 & 1 & & 1.761 \\
\hline $\begin{array}{l}\text { Formulation of the } \\
\text { problem, scientific } \\
\text { challenges, } \\
\text { subject, object } \\
\text { and limitation research }\end{array}$ & 18.54 & 6 & 1 & 4 & & 3.740 \\
\hline $\begin{array}{l}\text { Justification the chosen } \\
\text { method for problem to be } \\
\text { solved and } \\
\text { plan to be } \\
\text { developed }\end{array}$ & 18.49 & 6 & 4 & 5 & & 4.006 \\
\hline $\begin{array}{l}\text { Adjustment } \\
\text { and } \\
\text { adaptation of } \\
\text { existing } \\
\text { scientific- } \\
\text { methodical apparatus }\end{array}$ & 49.74 & 7 & 6 & 5 & & 5.000 \\
\hline $\begin{array}{l}\text { New } \\
\text { scientific- } \\
\text { methodic } \\
\text { al } \\
\text { apparatus development }\end{array}$ & 114.36 & 7 & 7 & 7 & & 5.488 \\
\hline $\begin{array}{l}\text { Development of the basic } \\
\text { data } \\
\text { accumul } \\
\text { ation to } \\
\text { use }\end{array}$ & 34.46 & 2 & 5 & 6 & & 2.273 \\
\hline $\begin{array}{l}\text { Development of the } \\
\text { methods of observation, } \\
\text { laboratory and field } \\
\text { experiments, testing }\end{array}$ & 21.98 & 2 & 3 & 3 & & 1.900 \\
\hline
\end{tabular}


The grid $T-C$ allows an assumption about positive correlation between these parameters. The correlation coefficient is equal 0,711 , which means a strong connection.

The next step is function $T=f$ (C) development based on the regression technique. Regression coefficients were calculated based on the well-known standard approaches (Zadeh, 2002). The following functions in accordance with the linear, exponential and exponential dependence have been calculated:

$$
T=16.857 \cdot C-19.592
$$

$$
\begin{aligned}
& T=8.501 \cdot e^{0.358 \cdot C} \\
& T=8.651 \cdot C^{1.062}
\end{aligned}
$$

Here $T$ is labor intensity, expressed as a weighted average of the average time length of R\&D phase. Dependency graphs $T$ of $C$ are shown in Figure 4.

Error of linear approximation is $48.50 \%$, exponential - 9,63\% and power - 14,19\% respectively. So exponential regression is the only one that properly meets demands of accuracy of calculation.

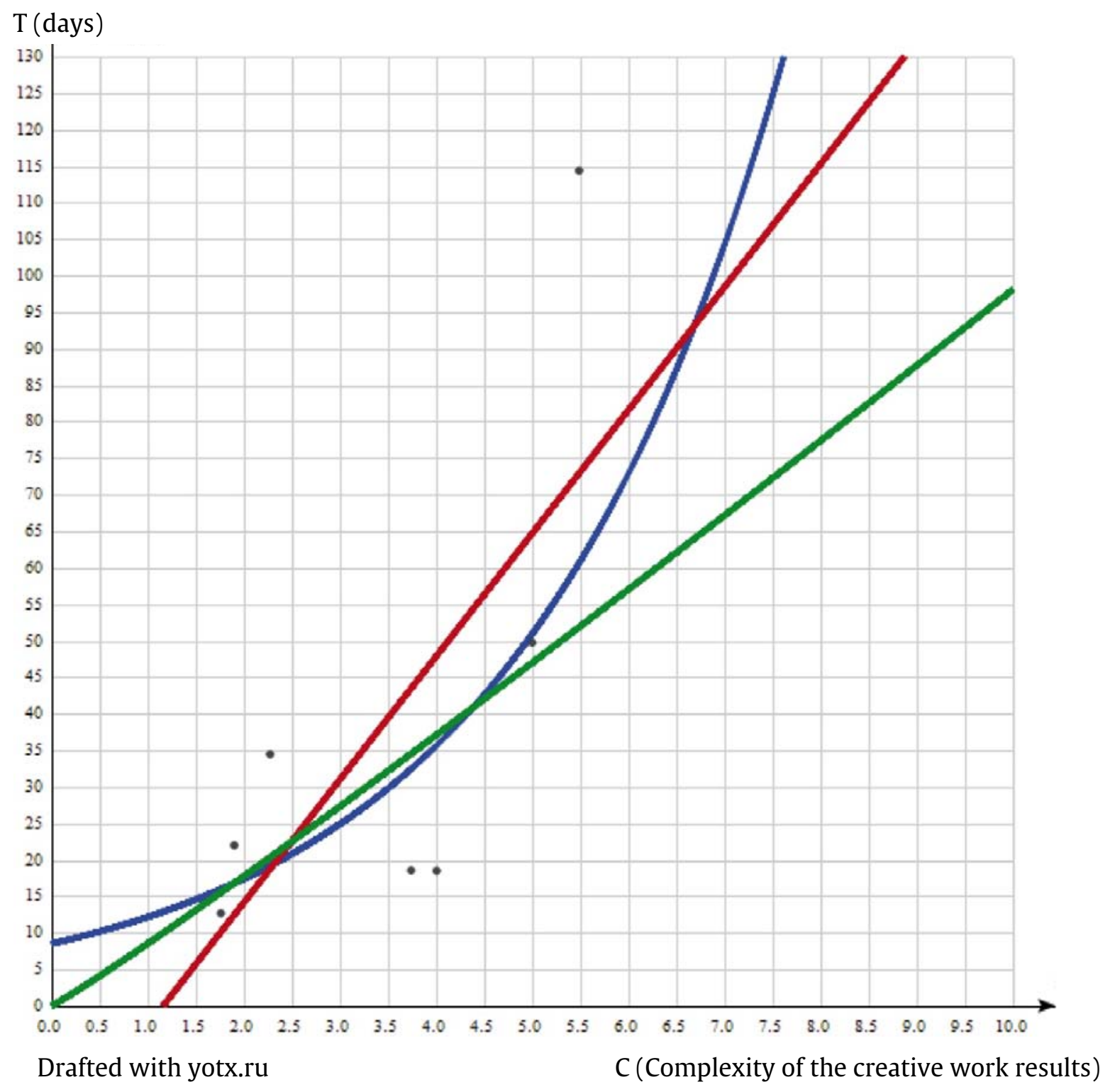

Figure 4. Linear (red line), power (green) and exponential (blue line) regressions that define dependence $T$ of $C_{c}$ 
For example, if a peer review, after appropriate procedures fuzzification and defuzzification gives the value of Competence Complexity $C_{c}$ equal 6.5 , it would need $88 \pm 8.5$ days, within errors, to get the results. Thus, we get an approximation for creative work dependence of the labor intensity dependence on Competence Complexity of the product, which can be used to determine the labor intensity of the creative project, depending on the complexity of the expected product.

\section{CONCLUSIONS}

The definitions for creative work and creative work product were developed to carry out work measurement and provide norm-fixing for creative work.

An addition to the basic concept and approaches of the complexity theory were developed for norm fixing and measurement if it is about creative work. Under principles of the fuzzy logic basic terms were defined to consider the specifics and structure of creative issues that enable one to quantify expert estimation to monetize the results of creative work.

The obtained dependence $T$ of $C$ enables the estimation of the time expenditure of creative projects.

\section{REFERENCES}

Botashev, R.A. (2011). Problems and ways of perfection of system of norms and work specifications to innovative economy. Scientific Journal of KubSAU, 71 (07), 1-23. http://ej.kubagro.ru/2011/07/pdf/15.pdf

Changli, I.I. (1973). Labor. Sociological aspects of the theory and methodology of the research carrying out. Moscow: Science.

Chapra, S. (2008). Numerical methods for engineers (6th ed). McGraw-Hill.

Durnev, R.A., Zhdanenko, I.V. (2012). R\&D laboriousness estimation in the life safety science branch: problems, ideas, approaches. VNIIPGOChS - Emercom of Russia, Moscow.

Durnev, R.A., Zhdanenko, I.V. (2014). About the Project of the Technique of the Assessment of Labour input and Cost Research and Developmental Works. Modern high technologies, 1, 19-28. http://www.toptechnologies.ru/ru/article/view?id=33623.

Feoktistova, O.A. (2014). Norm-setting of research work: methodological approaches. E-journal "Naukovedenie", 5(24), 1-20. http://naukovedenie.ru/PDF/109EVN514.pdf

Florida R. (2012). The Rise of the Creative Class, 2012, New York, Perseus Book Group

Genkin B.M. Economy and sociology of the labor: subject book for high education ( $7^{\text {th }}$ ed). Norm. - Moscow.

Ibragimov, A.U., Ibragimova, L.A., Karavayeva, M.V. (2012). Assessment of commercial enterprise personnel competence using fuzzy logic method. Vestnik of the Samara State Aerospace University, 1 (32), 242-249.

Karyakin, A.M., Grubov, E.O. (2012). Laboriousness estimation approach of research, scientific and development works in power engineering with fuzzy expert judgments. Vestnik IGEU, 3, pp. 1-6.

Kleiner, G.B. (2004). Awareness about knowledge management. Voprosy Economiki, 1, pp. 151 -155.

Kushnir, A.B. (2010). The creative work specialties in the terms of it norm-fixing and measurement. Vestnik NII Truda, 23 (34), pp. 64-66.

Kushnir, A.D. (2007). Creative work estimation and remuneration labor. Ph.D thesis. Moscow.

Kutsenko, V., Udovitchenko, V., Opaleva, I. (1998). Education as a factor of stability and homeland security. Economy of Ukraine, 1, $12-21$.

Luck A.N. (1978). Psychology of creativity. Science, - Moscow.

Makarov, V.L., Kleiner, G.B. (2007). Microeconomics of knowledge. Economika Moscow.

Makhlup, F. (1962). The Production and Distribution of Knowledge in the United States. Princeton University Press.

Packlin, N.B. (2004). Adaptive models of fuzzy logic for non-linear dependence in complex structures to be defined. PhD thesis. Izhevsk.

Richardson, W.J. (1971), Measurement of work using multiple regression indirect. The 
International Journal of Production

Research, Vo 4, 4, 301-312.

Rosstat. (2017). Work and Employment in Russia. Moscow: Rosstat. Retrieved from http://www.gks.ru/free_doc/doc_2017/trud_ 2017.pdf.

Serbinovskiy, B.Y., Kalmykova, N.G., Botashev, R.A. (2013). Development of selfemployment of the population and the problem of rationing creative activities in the RnD-organizations: theoreticmethodological aspects of new knowledge, product, technology and equipment. Part 1. E-journal Engineering journal of Don, 1. http://www.ivdon.ru/en/magazine/archive/ n1y2013/1521.

Sharin, Yu.S., Yakimovithc, B.A., Tolmatchev, V.G., Korshunov, A.I. (1999). Theory of complexity. ISTU Publishing House.

Shevchenko, N.Yu. (2009). Fuzzy logic using while human resources of enterprises are managed. Economic sciences. http://www.rusnauka.com/11EISN_2011/Ec onomics/5_85009.doc.htm.

Statute about project of Skolkovo innovative center participant title in the wording of Jun. 20. (2016). Retrieved from http://sk.ru/net/participants/p/documents.a spx.

Uvarova, L.I. (1982). Science as society capacity power. Moscow: Science.

Yasin, E.G. (2007). Modernization and society. Voprosy Economiki, 5, pp. 4-29.

Yu.G. Odegov, R.A. Galiakhmetov, S.V. Malinin, L.S. Babynina, Yu. V. Fedorov, M.R. Galiakhmetova, R.L. Fominykh. (2016). Work norm-setting: from theory to application in the modern company, monograph ( $1^{\text {st }}$ ed.). Izhevsk: PH ISTU named after M.T. Kalashnickov.

Zadeh, L. (2002). From computing with numbers to computing with words - from manipulation of measurements to manipulation of perceptions. International Journal of Applied Math and Computer Science, vol. 12, 3, pp. 307-324.

\section{ABOUT THE AUTHORS}

Marina Galiakhmetova, email: galiakhmetova.mr@mail.ru

Dr. Marina Galiakhmetova is the Associate Professor of the Enterprise Economics Faculty in Kalashnikov Izhevsk State Technical University named after M.T. Kalashnikov, Russia.

Dr. Vladimir Koretskiy is the Associate Professor of the Enterprise Economics Faculty in Kalashnikov Izhevsk State Technical University named after M.T. Kalashnikov, Russia.

Ms. Irina Mardanova is the HR Manager at Bashneft-Treid LTD Udmurtia Regional Brunch of Izhevsk, Russia.

Dr. László Józsa is the Professor at J. Selye University, Komarno, Slovakia. 